Association for Information Systems AIS Electronic Library (AISeL)

Wirtschaftsinformatik Proceedings 2001

Wirtschaftsinformatik

September 2001

\title{
Influencing Factors of Electronic Commerce Adoption by Small- and Medium-sized Enterprises in Australia
}

Sandy Chong

Curtin University of Technology, chongS@cbs.curtin.edu.au

Follow this and additional works at: http://aisel.aisnet.org/wi2001

\section{Recommended Citation}

Chong, Sandy, "Influencing Factors of Electronic Commerce Adoption by Small- and Medium-sized Enterprises in Australia" (2001). Wirtschaftsinformatik Proceedings 2001. 68.

http://aisel.aisnet.org/wi2001/68

This material is brought to you by the Wirtschaftsinformatik at AIS Electronic Library (AISeL). It has been accepted for inclusion in Wirtschaftsinformatik Proceedings 2001 by an authorized administrator of AIS Electronic Library (AISeL). For more information, please contact elibrary@aisnet.org. 
In: Buhl, Hans Ulrich, u.a. (Hg.) 2001. Information Age Economy; 5. Internationale Tagung Wirtschaftsinformatik 2001. Heidelberg: Physica-Verlag

ISBN: 3-7908-1427-X

(C) Physica-Verlag Heidelberg 2001 


\title{
Influencing Factors of Electronic Commerce Adoption by Small- and Medium-sized Enterprises in Australia
}

\author{
Sandy Chong \\ Curtin University of Technology
}

\begin{abstract}
Summary: The emergence of the Internet has allowed Small- and Medium-sized Enterprises (SMEs) to compete effectively and efficiently in both domestic and international markets [PoSw91]. However, the resistance and mismanagement of SMEs to the adoption of Electronic Commerce often impedes such leverage. This study aims to develop a model of Electronic Commerce adoption to assist those SMEs that are considering or are currently conducting their business using the Internet. Based on an extensive analysis of secondary sources, mainly existing adoption and technology diffusion literature, and complemented through a survey that is currently undertaken in Australia, factors that potentially influence the adoption and implementation success of Electronic Commerce for SMEs have been investigated. Applicability of the proposed framework will be empirically demonstrated using the results of surveys followed by in-depth case studies.
\end{abstract}

Keywords: Business-to-business Electronic Commerce, Adoption and Diffusion, Internet, Small-and Medium-sized Enterprises, Cross-coutnry studies.

\section{Introduction}

Electronic Commerce has changed and is still changing the way business is conducted around the world. The commercialisation of the Internet and World Wide Web (WWW) has driven Electronic Commerce to become one of the most important media for facilitating the sharing of business information within organisations and between business partners. It was estimated by the year 2004, the value of worldwide Electronic Commerce will reach US\$ 6.8 trillion [Forr01], while the Asia Pacific region will have Electronic Commerce revenue of US\$2.4 trillion by year 2005 [GaGr01].

In many cases, researchers indicate that the Internet and Electronic Commerce will have significant positive effects on the traditional value chain and business processes [BeWi95]. Such improvement requires the (re-)development and application of new concepts and models to allow Small- and Medium-sized Enterprises 
(SMEs) to take advantage of the many benefits of Electronic Commerce. In a globalised economy with less and less opportunities for regional and niche market positions, the adoption and successful deployment of Internet technology into an integrated Electronic Commerce business approach becomes a strategic necessity.

\section{Research Objectives}

The purpose of this paper is to identify a comprehensive set of potential determinants influencing the successful adoption of Electronic Commerce. The specific objective of this research is to construct a generic or generalised model of Electronic Commerce adoption and deployment for SMEs.

The above objectives can be translated into the following research questions:

- What factors facilitate or inhibit the adoption of Electronic Commerce in Small- and Medium-sized Enterprises?

- What adoption or implementation processes do Small- and Medium-sized Enterprises go through to successfully adopt Electronic Commerce?

This research paper is focused on answering the first question, but is part of a larger study aimed at investigating both questions in depth.

\subsection{Scope of the Study}

In this research, the scope of Electronic Commerce applications is limited to the utilisation of Internet as the technology infrastructure to communicate, distribute and conduct information exchange and business transactions with business partners. Due to the differences in the strategic success factors and the underlying technologies, a classification into Business-to-Business Electronic Commerce and Business-to-Consumer Electronic Commerce has become common amongst previous studies [KaWi97; GaTo96]. The difference appears to be the use of the Internet to automate business transactions between companies for business-to-business Electronic Commerce, while the other, business-to-consumer Electronic Commerce, is the use of Internet to sell merchandise or provide services to customers in much the same way as a store or a catalogue [GaTo96]. The overwhelming growth rate of the Internet since the commercialisation in the early 1990's make it the most utilised Wide Area Network platform even for business-to-business communications and make the further substitution of previous platforms highly likely throughout the next decade. It is estimated that $53 \%$ of Electronic Commerce capabilities are estimated to be based on business-to-business relationship and the Forrester Research predicts that business-to-business Electronic Commerce will hit US\$3.6 trillion by 2005 in US alone [GaGr01]. This research 
will purposefully focus on organisations that use Electronic Commerce to carry out transactions and interactions that effectuate existing business relationship or pre-existing contractual relations between its trading partners (i.e. Business-to-Business Electronic Commerce).

\section{Facilitating and Inhibiting Factors of EC Adoption}

According to Rogers [Roge95], adoption is a decision to make full use of an innovation as the best course of action whereas rejection is a decision not to adopt an available innovation. In this study, adoption is therefore defined as the decision by an organisation to make use of Electronic Commerce (EC) to conduct business with its trading partners. There are two levels of adoption. Initially, innovation must be purchased, adopted and acquired by an organisation. Subsequently, it must be accepted by the ultimate users in that organisation and community [MaRi86]. In this study, it is proposed that several factors influence different levels of EC adoption for the organisation. In the absence of empirical studies to assist in the selection of the most significant variables for EC adoption, all relevant factors have been identified and grouped into broad categories of internal and external environment factors. The distinctions into internal and external environment factors is made to distinguish between organisation-specific (and organisation-determined) factors and factors that are imposed (and determined) from outside the organisation in the adoption decision and deployment process of EC. A more comprehensive review of the literature these influencing factors and detailed explanation of the research model can be found in Chong [Chon99].

\subsection{Focus of this Paper}

On top of the theoretical foundations mentioned previously, further review of related literature has been covered to develop a proposed model of Electronic Commerce adoption for Small- and Medium-sized Enterprise. At this present, it is the purpose of the paper to direct its discussion towards the identification of factors that exert influence on adoption of Electronic Commerce using the preliminary findings of the survey. 


\section{Research Methodology}

Preliminary interviews with four Australian SMEs ${ }^{1}$ were conducted in April and September of 1999. This provided direction to what adoption factors are imperative to SMEs and was supported by an extensive literature review, this contributed to the design of the proposed research model [Chon99]. This exploratory study believes that the factors proposed in the research model will make key contribution to the adoption of Electronic Commerce for small businesses. A survey instrument was developed and pilot-tested to capture the information reflecting the perceptions and practice of those adopting EC, specifically what internal or external environment factors affect the adoption of EC and the degree of influence. In order to focus on SMEs, assistance was sought from governmental and research institutions in Australia to develop a database of SMEs and contact details of target respondents. In order to add a richer and more detailed refinement beyond what is possible with the survey approach [Yin, 1994], the overall empirical analysis will be supplemented by a detailed examination of three firms using a multiple case study approach. The case studies will entail personal interviews with key decision-makers within the selected firms, to reconfirm the validity of the model developed and to investigate in depth the adoption processes on the background of internal and external environment factors.

\subsection{Current Status of the Research}

Between October and December of 2000, the researcher has conducted a crosscountry survey in Australia. As the survey was intended to apply over a wide geographical area, the chosen method of delivery was a combination of email, web and mail survey. During the first-wave of data collection, 150 survey questionnaires were disseminated by email and mail with a cover letter stating the objective of the study and the web address of the online survey. The surveys sent out are personally addressed to the director or owner of the firms. At the time of writing, 38 SMEs have responded from Australia via Web and fax. In order to improve response rate, reminders were sent out to target respondents two weeks after the first mail-out and the second-wave of survey mail-out has commenced.

1 Definition of Small- and Medium-sized Enterprises (SMEs) in Australia is any business employing less than 20 people; and 20 or more but less than 200 people for medium business. For further definitions of SMEs, please refer to http://sbdc.gov.au. 


\section{Preliminary Findings}

Preliminary analysis has been conducted using the limited sample size of not more than fifty responses, which the study has collected so far. Descriptive and some correlational analysis has been carried out to understand the profiles and behaviour of the key variables. However, it should be noted that the results have yet to be conclusive.

\subsection{Sample Profile}

The thirty-eight SMEs from Australia that have responded to the survey, represent a $25 \%$ response rate. From the preliminary findings, the majority of the responding SMEs employ less than 50 employees (52.6\%), have a company turnover between \$1 million and \$15 million in 1999 (52.6\%) and are legally registered as Proprietary Limited companies $(68.4 \%)$. The industry sectors of the responding firms range across manufacturing $(36.8 \%)$, retail $(21.0 \%)$, wholesale $(21.0 \%)$, export \& import trade $(15.8 \%)$, with $5.2 \%$ in other industries. The age of the responding SMEs was also quite spread with $26.3 \%$ of the companies between 2 and 5 years old, $31.5 \%$ between 6 and 10 years old, and $42.1 \%$ more than 10 years old. Almost half of the respondents hold the position of Managing Director (47.4\%), while more than half of the SME owners have education level of Diploma or less (23.7\% of them have up to secondary level education and $36.8 \%$ are diploma holders).

\subsection{Categories of Adopters}

Additional data indicates that the responding firms also had a wide range of experience with EC adoption and implementation. Some firms were relatively new to the EC mode of operations (38\% had less than 6 months EC experience), while others had used it for many years ( $26 \%$ had greater than 5 years experience). A sufficient range of adopters from early to late adopters was represented in the sample. The high percentage of late adopters is consistent with the natural expectation of the relatively new and growing business practice of EC.

\subsection{Reasons for EC Adoption}

The respondents' perceptions of the reasons for adopting EC are reported in Table $1^{2}$. In this section, responding SMEs were asked to rate reasons for their company's decision to adopt EC according to their level of importance.

2 The responses from Table 1 to 4 have been ranked according to their importance as indicated by the means of the 38 responses 


\begin{tabular}{lc}
\hline Main Reasons & Overall Means \\
\hline Easily \& quickly disseminate product information & 3.94 \\
Save costs / lower prices & 3.91 \\
Gain quick turnaround for orders / purchases & 3.88 \\
Improve productivity & 3.74 \\
\hline Improve image \& reputation & 3.62 \\
Simply eager \& enthusiastic to explore any possibilities that the Internet may & 3.62 \\
offer & \\
Showcase your company's products & 3.56 \\
Increase sales & 3.47 \\
Gain global reach of customers / suppliers & 3.44 \\
\hline
\end{tabular}

Respondents scored each item on a 5-point scale where $5=$ Very important and $1=$ Very unimportant.

Table 1: Reasons for EC Adoption

The above implies that easy and quick dissemination of product information (3.94) has been the most important reason for the SMEs to adopt EC, followed by saving costs (3.91) and gaining quick turnaround (3.88) for orders and purchases in their business. On the other hand, less importance is placed in increasing sales (3.47) and gaining global business (3.44) as reasons to adopt EC. However, the average range of means is only 0.50 , therefore further data collection is needed to reveal the significance of these differences.

\subsection{Barriers Prior to EC Adoption}

\begin{tabular}{lc}
\hline Barriers Prior Adoption & Overall Means \\
\hline Initial set-up costs & 3.47 \\
Lack of in-house expertise or competence & 3.38 \\
\hline Security issues & 3.35 \\
\hline Customers and/or suppliers not EC ready & 3.26 \\
Company not EC ready & 3.26 \\
On-going operational costs & 3.26 \\
Lack of critical mass among business partners & 3.21 \\
Reliability of the Internet & 3.09 \\
Lack of perceived needs & 3.09 \\
Don't know enough about EC & 2.91 \\
Unfamiliar with IT in general & 2.79 \\
Legal issues and standards & 2.62 \\
Wait and see & 2.56 \\
Currently VAN-based, adequate-no need to migrate to Internet infrastructure & 2.26 \\
\hline
\end{tabular}

Respondents scored each item on a 5-point scale where $5=$ Very important and $1=$ Very unimportant.

Table 2: Barriers - Bfore Adopting EC 
Respondents were also asked to rate the concerns that their company had to deal with before the adoption of EC.

Apparently, the dominant barrier prior to EC adoption is the concern about initial costs (3.47), while on-going cost is perceived to be less important (3.26). This indicates a possible lack of awareness that the on-going costs to maintain EC business practice is usually much higher than initial costs, as in any IT investment. Other barriers are related to readiness issues - where SMEs have doubts about their ability to make full use of EC due to the lack of in-house expertise (3.38) or competence. In addition, security issues (3.35) also ranked high on the list of concerns SMEs faced before the adoption of EC. The lack of immediate needs such as the wait and see attitude (2.56) and the adequacy of migrating to Internet infrastructure (2.26) are perceived to have less importance as barriers prior to the adoption of EC.

\subsection{Barriers to EC Implementation}

After the companies have decided to adopt EC, the perceived problems that companies have to face or manage while implementing $E C$ were also investigated.

\begin{tabular}{lc}
\hline Barriers & Overall Means \\
\hline Lack of managerial time & 3.62 \\
Shortage of skills & 3.29 \\
\hline Excessive costs & 3.21 \\
\hline Lack of EC or IT knowledge & 3.06 \\
Lack of systems integration or unstructured systems & 2.88 \\
Company too small & 2.88 \\
Lack of reliable technical advice and support & 2.79 \\
Lack of suitable infrastructure in the country & 2.44 \\
Lack of enthusiasm towards computing, IT and EC & 2.29 \\
Inappropriate economic climate & 2.26 \\
\hline
\end{tabular}

Respondents scored each item on a 5-point scale where $5=$ Very important and $1=$ Very unimportant.

Table 3: Barriers - While Implementing EC

After making the decision to adopt EC, responding SMEs face obstacles in the implementation of EC due to the lack of resources such as managerial time (3.62), skills (3.29) and finance (3.21). The lack of managerial time is particularly explicable as most facilitators of EC strategies in most SMEs are directors or owners themselves, who are, inevitably, busy executives. This is an indicator of the need for training and education to be provided on both technical and management skills in the EC environment. Morale and technical aspects of the adoption appear to have lesser importance to SMEs once they have decided to adopt EC. 


\subsection{Perceived Benefits}

The respondents' perceptions of the impacts of EC are reported in Table 4. The key informants were asked to indicate the extent of various direct and indirect benefits received at the time of EC adoption.

\begin{tabular}{lc}
\hline Direct Benefits & Overall Means \\
\hline Saving time in searching information & 3.94 \\
\hline Long term business partnership (gain'g/improv'g long term biz. alliances) & 3.79 \\
\hline Savings in costs (communications, overheads, printing \& advertising costs, etc. & 3.76 \\
Increased sales & 3.53 \\
Secure returning customers (improved customer retention) & 3.21 \\
Generate short term revenues (eg. direct sales) & 2.68 \\
Indirect Benefits & \\
\hline Opening potential business opportunities & 3.94 \\
New business initiatives & 3.85 \\
Access to new distribution channels & 3.79 \\
Effective publicity, advertising and marketing (eg. improve awareness \& image) & 3.74 \\
Ongoing business transformation (eg. improve procuremt or inventory mgmt.) & 3.50 \\
\hline
\end{tabular}

Respondents scored each item on a 5-point scale where $5=$ Strongly agree and $1=$ Strongly disagree.

Table 4: Perceived Benefits

As indicated above in the Direct Benefits section, time savings (3.94), ability to gain long-term business partnership (3.79), and cost savings (3.76) are perceived by respondents to be greater than generating sales and customer retention. This suggests that most responding SMEs are still unable to generate short-term revenues and secure existing customers for the company from the adoption of EC. As for Indirect Benefits, most respondents found the adoption of EC had opened more potential business opportunities for them (3.94), gained new business initiatives (3.85), and allowed them access to new distribution channels (3.79). This implies that although current sales generate from EC are considered as moderate, future business opportunities and long term sales or revenues are anticipated to be high.

Overall, the results indicated that most respondents received slightly higher level of indirect benefits than direct benefits, but it should be noted that this result is not statistically significant and further data is needed to clarify this.

\subsection{Areas of Internet Usage}

To understand the most common areas of Internet usage by the firms, respondents were asked to rate the extent of usage on a scale of $1=$ very little to $5=$ very often and $0=$ not used. Table 5 summarises these results. 


\begin{tabular}{lc}
\hline Internet Usages & Overall Means \\
\hline Communication with customers, suppliers \& industry groups & 2.85 \\
Collaboration with customers, suppliers \& industry groups & 2.29 \\
Research \& development & 2.21 \\
\hline Publicity, promoting \& advertising of goods \& services & 2.18 \\
Online selling of goods \& services & 1.12 \\
\hline
\end{tabular}

Table 5: Areas of Internet Usage

It appeared that Communication with customers, suppliers and industry groups (2.85) is the most common Internet usage of responding firms. Collaboration with customers, suppliers and industry groups (2.29) was the second most common function, followed by Research \& Development (2.21). Publicity/ promoting/ advertising (2.18) and Online selling (1.12) were used less by respondents in their business. This is partly expected because the majority of the respondents belong to the manufacturing industry. Although overall usage is not high, it is expected to grow over time.

\subsection{Level of Internet Usage}

While the above analysis explores the areas of Internet usage, the scores on the questions were added to give an index of the extent to which Internet potential is being utilised. Figure 1 shows the distribution of the Total Utilisation of Internet.

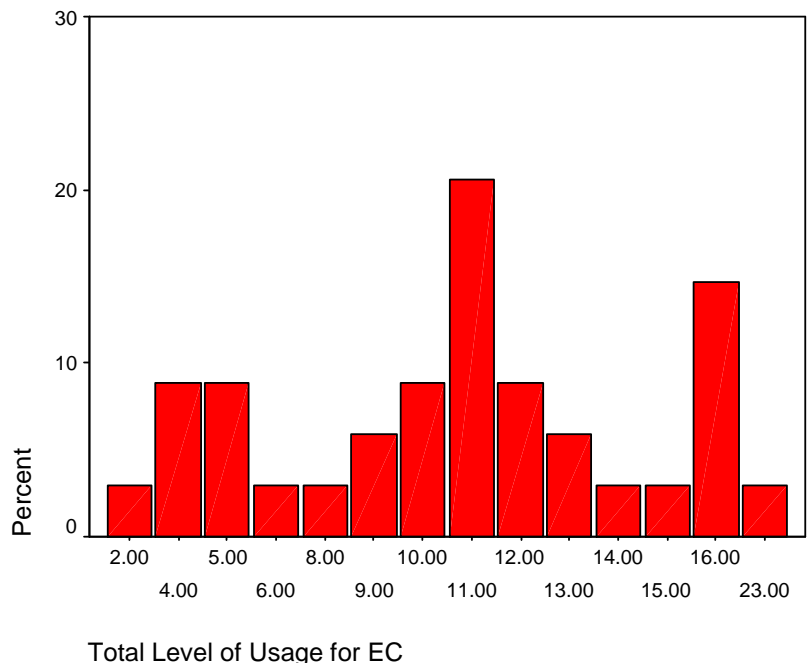

Figure 1: Total Level of Internet Usage 
The graph appears to be tri-modal. If the two extremes (lower and upper modes) were ignored, the pattern would resemble a normal distribution, which might be expected. There is a distinct lower group which suggests marked under-utilisation of Internet and an upper most group, also very distinct, tend towards the fuller utilisation of the presently understood potential of Internet. This is considered normal with technology adoption, as there will be a group of firms that utilises the technology frequently once it has been adopted; while some other groups of firms use less or under-utilise the applications and functions of technology. Overall, the norm shows that utilisation is still relatively moderate and restricted.

Apart from descriptive findings, the survey has also investigated relationships such as the length of adoption with the level of satisfaction, state of adoption with overall satisfaction and innovation characteristics with overall satisfaction of Electronic Commerce adoption. The study of these relationships is under analysis and results will be published at a later date.

\section{Conclusion \& Further Research}

Although valuable information has emerged through the gathering of data and measurement of the key adoption factors of Electronic Commerce, the sample size is not yet large enough to draw any significant conclusion from the results. This research has identified the factors exerting influence on the adoption of Electronic Commerce in SMEs. A multi-methodological approach will be required to capture the reach of the adoption and the richness of the deployment processes. Multivariate causal analysis investigating the links between the factors and impact on Electronic Commerce adoption and success will be conducted. However, at this stage, the intention of the researcher to explore the essential relationships of the factors affecting Electronic Commerce adoption and present the results at the conference.

\section{References}

[BeWi95] Benjamin, R., and Wigand, R.: "Electronic markets and virtual value chains on the information superhighway", Sloan Management Review, Cambridge, Winter, 36(2) (1995), pp. 62-73.

[Chon99] Chong, S.: "The diffusion of electronic commerce: A cross-country of adoption and integration in small- and medium-sized enterprises", Workshop on Information Systems Research (WAWISR), (1999), Murdoch University, November, Western Australia, Perth. 
[Forr01] Forrester Research: "Worldwide eCommerce Growth", (2001), URL: http://www.forrester.com/ER/Press/ForrFind/0,1768,0,FF.html

[GaTo96] Gagnon, Y. and Toulouse, J.: "The behaviour of business managers when adopting new technologies", Technological Forecasting and Social Change, 52 (1996), pp.59-74.

[GaGr01] Gartner Group: "Gartner says Asia Pacific and Europe to account for nearly half of worldwide B2B Internet Commerce transactions by 2005", Gartner Research, Press Release, San Jose, California, April 2, (2001), URL: http://www4.gartner.com/ 5_about/press_room/pr20010402a.html

[KaWi97] Kalakota, R. and Whinston, A.: Electronic Commerce: A Manager's Guide, Addison-Wesley Longman.

[MaRi86] Manross, G. and Rice, R.: "Don't Hang Up: Organisational Diffusion of the Intelligent Telephone", Information and Management, 10 (1986), pp.161-175.

[PoSw90] Poon, S. and Swatman, P.: "An exploratory study of small business Internet commerce issues", Information and Management, 35(1) (1999), pp.9-18.

[Roge95] Rogers, E.M.: Diffusion of Innovations, 4th Ed. The Free Press, New York, NY. (1995)

[YinR84] Yin, R.: Case study research: design and methods, Sage Publications, California. (1984) 